\title{
Sobre la presencia de Botrychium Iunaria en la Comunidad Valenciana
}

\author{
Juan J. Herrero-Borgoñón ${ }^{1 *}$, Carlos Fabregat ${ }^{2}$ \& Jesús Riera ${ }^{2}$ \\ ${ }^{1}$ Parques y Jardines Singulares y Escuela Municipal de Jardinería y Paisaje (Ayuntamiento de Valencia), C/ Antonio

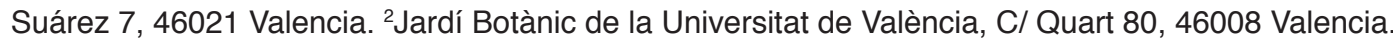

\section{Correspondencia}

J.J. Herrero-Borgoñón

e-mail: juan.j.herrero@uv.es

Recibido: 30 noviembre 2017

Aceptado: 18 diciembre 2017

Publicado on-line: diciembre 2017
About the presence of Botrychium lunaria in the Valencian Community

Palabras clave: Pteridophyta, corología, Castellón, España.

Key words: Pteridophyta, chorology, Castellón, Spain.
Botrychium lunaria (L.) Sw. es un pequeño pteridófito, muy escaso en el área oriental ibérica, que en la Comunidad Valenciana únicamente había sido citado en dos localidades de la provincia de Castellón, en las que no se ha podido volver a encontrar desde la década de los años 80 del siglo pasado.

La primera referencia de esta especie en Castellón corresponde a Vigo (1981), que la indicó en las "laderas orientales del Penyagolosa", monte éste que representa la mayor altitud de la provincia. Vista la escasa concreción de la cita, se optó por consultar el pliego sobre el que se basa la misma, aunque, tras su consulta, se comprobó que no aportaba ningún dato sustancial que permitiese precisar más su localización, pues la etiqueta que le acompaña solo indica "L'Alcalatén - vessants de la Penyagolosa, $1.550 \mathrm{~m}, 21-6-1980$, J. Vigo, R.M. Masalles, E. Velasco, X. Font, J.M. Ninot, BC 643772", donde el topónimo "L'Alcalatén" únicamente corresponde al nombre de la comarca en que se sitúa el área mencionada.

Afortunadamente, Josep Vigo nos proporcionó información adicional sobre el lugar en que recogió la especie, indicando que encontró apenas dos ejemplares "subiendo desde la Masia de les Mallades a la cima de Penyagolosa, siguiendo la cresta oriental de la montaña, hacia el Tossal de Fraga, en un lugar más bien pedregoso, aparentemente no muy adecuado para esta especie" (com. pers.).

Sobre la base de esta información, se puede estimar que la localidad en cuestión se situaría en la cuadrícula UTM 30TYK2656, en el término municipal de Chodos. A pesar de disponer de estas indicaciones, y de visitar repetidamente el área señalada por J. Vigo, no se han podido encontrar nuevos ejemplares hasta ahora, ni en ésta ni en otras zonas favorables del macizo de Penyagolosa, por lo que el pliego recogido originalmente sigue siendo el único testimonio de la presencia de la especie en el mismo.

La otra localidad en la que se ha citado $B$. lunaria corresponde al Puerto de las Cabrillas, puerto de montaña que se localiza entre Portell de Morella (Castellón) y La Iglesuela del Cid (Teruel), situación que ha propiciado el que la población allí encontrada haya sido asignada tanto a una como a otra provincia, dando lugar a algunos errores corológicos.

Basándose en el pliego que documenta su descubrimiento ("Castellón: Puerto de Cabrillas, pr. Portell de Morella, YK2988, 1.280 m, 25-VI1988, G. Mateo, VAL 59196"), y en otra recolección posterior ("Castellón: Portell de Morella, Puerto de las Cabrillas, YK28, 1.300 m, 28-V-1989, A. Aguilella, VAL 168596"), dicha población fue incluida en varias síntesis corológicas de la flora valenciana (Bolòs \& Romo, 1991; Serra et al., 2000). Por otro lado, también fue incluida en el catálogo florístico de la provincia de Teruel al ser citada en La Iglesuela del Cid, en el sector turolense del puerto (Mateo, 1990; López Udias, 2000).

El motivo de esta paradoja parece deberse a que la población, descubierta en la parte superior del puerto, se localiza precisamente en el límite entre las provincias de Castellón y Teruel, en 
un punto en el que una incorrecta señalización de los límites provinciales en la carretera que lo atraviesa favorece la confusión, más que al hecho de que la cuadrícula UTM que aparece en el pliego VAL 59196 no coincidiese con la situación real de la población. Hechas las comprobaciones pertinentes, se pudo verificar que la población en cuestión se situaría en Teruel.

No obstante, conviene indicar que los escasos ejemplares que se localizaron allí se desarrollaban en la cuneta de la mencionada carretera, que, con posterioridad, ha sido ensanchada, lo que plantea dudas acerca de su actual permanencia, más teniendo en cuenta que, desde la recolección de 1989, esta población no ha podido ser encontrada de nuevo.

A pesar de que estos datos descartaban la presencia de la especie en esta zona del noroeste de Castellón, en 2015 se descubrió una nueva población de $B$. lunaria en el mismo término de Portell de Morella, aunque en un punto distante varios kilómetros de la localidad del Puerto de las Cabrillas ("Castellón: Portell de Morella, Barranc del Grevolar, YK3194, 1.075 m, 5-V-2015, J. Riera, VAL 226836"). En dicho enclave se localizaron once ejemplares creciendo en los taludes umbrosos del barranco, en el seno de un pinar de Pinus nigra Arn. subsp. salzmannii (Dunal) Franco, sobre suelos pedregosos calcáreos y entre tapices de Festuca gautieri (Hack.) K. Richt. Por tanto en la presente nota se confirma la presencia actual de $B$. lunaria en la Comunidad Valenciana, y constituye la única localidad con referencias concretas hasta la fecha en dicho territorio.

\section{Agradecimientos}

A los Drs. Josep Vigo, Eulalia Velasco, Gonzalo Mateo y Ana M. Ibars, que nos facilitaron valiosa información, los dos primeros sobre la población de Penyagolosa, y los dos últimos sobre la población del Puerto de las Cabrillas. Al Servicio de Vida Silvestre de la Conselleria de Agricultura, Medio Ambiente, Cambio Climático y Desarrollo Rural (Generalitat Valenciana) que financió el trabajo "Situación de Botrychium lunaria en la Comunidad Valenciana", realizado por el primero de los autores, del que procede parte de la información aquí recogida.

\section{Referencias}

Bolòs, O. De \& Romo, A. M., Eds. (1991). Atlas corològic de la flora vascular dels Països Catalans, vol. 2. ORCA. Institut d'Estudis Catalans. Barcelona.

López Udias, S. (2000). Estudio corológico de la flora de la provincia de Teruel. Tesis Doctoral. Universitat de València.

Mateo, G. (1990). Catálogo florístico de la provincia de Teruel. Instituto de Estudios Turolenses. Teruel.

Serra, L., Fabregat, C., Herrero-Borgoñón, J. J. \& López Udias, S. (2000). Distribución de la flora vascular endémica, rara o amenazada en la Comunidad Valenciana. Generalitat Valenciana. Valencia.

Vigo, J. (1981). Noves dades per a la flora de Penyagolosa. Butll. Inst. Cat. Hist. Nat. 46 (Sec. Bot. 4), 101-106. 